\title{
ARTICLE Functional analysis of tomato calmodulin gene family during fruit development and ripening
}

\author{
Tianbao Yang ${ }^{1}$, Hui Peng ${ }^{1,2}$ and Gary R Bauchan ${ }^{3}$
}

Calmodulin is a ubiquitous calcium sensor to recognize the different developmental and/or stimulus-triggered calcium changes and regulate plant growth and development. However, the function of calmodulin remains elusive for fleshy fruit development. We performed expression studies of a family of six calmodulin genes (SICaMs) in tomato fruit. All calmodulins showed a double peak expression pattern. The first flat peak appeared at 10-30 days after anthesis, but their expression rapidly declined at mature green and breaker. Then a sharp and even higher peak came at turning/pink stages. Among six calmodulins, SICaM1 had the highest expression during fruit enlargement, whereas SICaM2 was the major calmodulin during fruit ripening. However, SICaMs showed different patterns in three ripening mutants rin, Nor and $\mathrm{Nr}$. In particular, at the stages corresponding to mature green and breaker, the expression levels of SICaMs in those mutants were significantly higher than wild-type. Furthermore, SICaMs, especially SICaM2 were upregulated by ethylene. Transiently overexpressing SICaM2 in mature green fruit delayed ripening, while reducing SICaM2 expression accelerated ripening. Our results suggest that SICaMs play double roles to regulate fruit ripening. Prior to the ethylene burst, the ethylene-independent repression of SICaMs might be critical for fruit to initiate the ripening process. After the ethylene burst, SICaMs could participate in the ethylene coordinated rapid ripening.

Horticulture Research (2014) 1, 14057; doi:10.1038/hortres.2014.57; Published online: 12 November 2014

\section{INTRODUCTION}

Fleshy fruits consist largely of soft succulent tissue, and contribute to a significant part of human diet for fibers, minerals and various nutraceuticals which are beneficial to human health. Right from the early stage of fruit set to ripening, fruit undergoes periods of cell division, cell expansion and finally ripening. ${ }^{1,2}$ Postharvest perishability and quality depends on the control of fruit maturation/ ripening process. Fruit ripening is a complex, yet genetically programmed process affected by external and internal cues. ${ }^{3,4}$ Tomato (Solanum lycopersicum) is an excellent model to study climacteric fruit development and ripening due to its relatively short generation time, a long known history of physiological, biochemical and molecular investigations and advancement in the development of genetic and molecular tools for this species. The pleiotropic ripening mutants in tomato have added greatly to the understanding of ripening in fleshy fruit. These mutants include ripening-inhibitor (rin), non-ripening (Nor) and never-ripe (Nr). The Rin and Nor genes encode a MADS-box and a NAC-domain transcription factor, respectively, and it is suggested that they regulate both ethyleneindependent and -dependent ripening processes. ${ }^{5} \mathrm{Nr}$ is directly involved in ethylene-dependent ripening because $\mathrm{Nr}$ encodes an ethylene receptor. ${ }^{6}$ However, the details of a developmental regulatory cascade remain to be defined. ${ }^{4,7}$

It is established that the divalent ion calcium is important in controlling fleshy fruit ripening and shelf-life. ${ }^{8-11}$ Calcium application can delay fruit ripening, and maintain fruit quality, in particular firmness, and thereby alleviate postharvest decay. It has been suggested that calcium acts through rigidifying the cell wall by crosslinking pectic acid residues ${ }^{12}$ and stabilizing cell membranes. ${ }^{13}$ Nevertheless, accumulating evidence indicate that calcium is a universal second messenger, and plays an important role in plant growth and development by mediating response to a variety of environmental and hormonal signals. ${ }^{14-16}$ Signal triggered intracellular calcium changes are perceived by calcium sensors. Calmodulin is a ubiquitous calcium sensor, and present in all plant cell types examined thus far. ${ }^{17-20}$ It can modulate the actions of diverse target proteins involved in almost all aspects of cell activity including cell division, cell elongation, ion transport, secondary metabolism, plant defense, etc. ${ }^{17-20}$

Based on genome sequence analysis, tomato has six calmodulin genes (S/CaMs), which are expressed in all organs, including fruits. ${ }^{21}$ SICaMs in vegetative tissues were highly responsive to a variety of biotic and abiotic stimuli such as ethylene, abscisic acid, benzothiadiazole and jasmonic acid. Silencing of SICaM2 and SICaM6 altered expression of defense-related genes and reduced resistance to pathogens. Accumulation of calmodulin mRNA and protein were also observed in tomato leaves after wounding or systemin treatment. $^{22}$ In addition, several calmodulin-target proteins have been reported in tomato fruits. For example, calmodulin can increase the activity of glutamate decarboxylase. Glutamate decarboxylase is a key enzyme for the biosynthesis of gamma-aminobutyric acid, ${ }^{23,24}$ a beneficial compound to human health. ${ }^{25}$ SUN belongs to the IQD family of calmodulin-binding proteins ${ }^{26,27}$ and controls fruit elongation. ${ }^{28}$ Recently, we characterized a family of calmodulinregulated transcription factor family SISRs during tomato fruit development. ${ }^{29,30}$ All SISRs were highly yet differentially expressed during fruit development and ripening. Most notably, the expression of SISR2 was scarcely detected at the mature green and breaker stages, two critical stages during the transition from fruit size enlargement to fruit maturation. The expression profiles of all seven

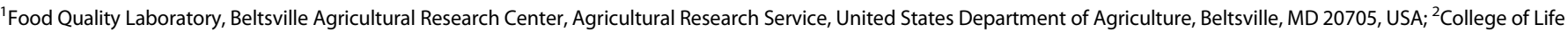

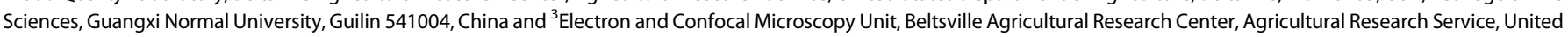
States Department of Agriculture, Beltsville, MD 20705, USA

Correspondence: TB Yang (tianbao.yang@ars.usda.gov)

Received: 27 August 2014; Revised: 2 October 2014; Accepted: 3 October 2014 
SISRs were altered in ripening mutants compared with wild-type fruit. However, so far, it is still not clear how and whether calcium/ calmodulin signaling is involved in fruit ripening. Here we report an expression analysis of the calmodulin gene family in wild-type tomato and ripening mutants, as well as the functional significance of a specific calmodulin gene to regulate fruit-ripening process.

\section{MATERIALS AND METHODS}

\section{Plant materials}

Tomato plants (S. lycopersicum cv 'Rutgers' and 'Moneymaker') were grown in greenhouse at $28{ }^{\circ} \mathrm{C}$ and $16 \mathrm{~h} / 8 \mathrm{~h}$ (light/dark). 'Rutgers' was used for gene expression studies, whereas 'Moneymaker' was mainly used for functional studies by transient transformation. The ripening mutants rin, Nor and $\mathrm{Nr}$ were all in 'Rutgers' background. Tomato fruit development stages were divided into fruit enlargement stages counted by days post anthesis (DPA) and the visual color changes during development and ripening set by USDA (http://www.ba.ars.usda.gov/hb66/tomato.pdf). Mature green fruit was the first stage after the maturation of the seeds. At this stage, the fruit was fully expanded with a green surface. Breaker stage fruit was defined when first visible sign of carotenoid accumulation was evident. This stage was followed by, turning, orange, red ripe and over-ripe stages. The equivalent stages to mature green, breaker and red stages for three ripening mutants are 45,50 and 65 DPA, respectively. The pericarp color of those mutants keeps green before 50 DAP. At 65 DPA, their fruit surfaces show the different degrees of yellowness. Leaves and roots were collected from the third fully opened leaves from top and $20 \mathrm{~mm}$ long roots counting from root-tip of 3-month old plants, respectively. Flowers were the whole immature buds $(\sim 12 \mathrm{~mm})$.

\section{Ethylene treatment}

The greenhouse-grown fruits at the mature green stage were held under ambient conditions overnight to reduce harvest shock prior to treatment Thereafter the fruit were sealed in a jar with 100 ppm ethylene for different time periods. Pericarp tissue excised from the fruit was frozen in liquid nitrogen and stored in $-80^{\circ} \mathrm{C}$.

\section{RNA extraction and RT-qPCR}

Total RNA was isolated from frozen tissue using RNeasy Plant Mini Kit following the manufacturer's instruction (Qiagen, Valencia, CA, USA). Reverse transcription and qPCR were performed as described ${ }^{29}$. Briefly, one $\mu \mathrm{g}$ of total RNA was used to synthesize CDNA with iScript ${ }^{\mathrm{TM}}$ kit (Bio-Rad, Hercules, CA, USA), RT-qPCR analysis of CDNA was performed on a CFX96 Real-time System (Bio-Rad). Gene specific primers listed in Table 1 were designed with the Primer3 software (http://frodo.wi.mit.edu/primer3/). Relative fold difference $(N)$ was the number of the treated target gene copies relative to the untreated control gene copies and is calculated as follows: $N=2^{\Delta C q} . \Delta C q$ was the difference in threshold cycles for S/CaMs targets and the actin internal reference. Relative gene expression (fold changes) was calculated based on $N$ with the lowest value as 1 . Student's $t$-test $(p<0.05)$ was used to determine the significant difference of relative expression of individual genes among different treatments and controls (Microsoft Excel 2007). The results are based on at least three repeats in three independent experiments.

Construction of Ti plasmids carrying sense- and antisense- SICaM2 Full length SICaM2 were amplified from a mixture of fruit tissues by Pfx DNA polymerase, and subcloned to TA cloning Kit (Life Technology, Grand Island, NY, USA) using gene-specific primers (Table 1). The nucleotide sequences of the positive clones were confirmed by sequencing. The full length of SICaM2 were subcloned into $\mathrm{PDL} 198,{ }^{31}$ a derivative of pCambia1300 in either senseand antisense- orientations in the sites of Kpn I and BamH I downstream of 355 promoter, and introduced into Agrobacterium tumefaciens strain GV3101. The positive clones were verified by PCR using gene-specific primers.

\section{Fruit agroinfiltration}

Agroinjection of tomato fruit was carried as described by Orzaez et $a l^{32}$ Briefly, Agrobacterium cultures were grown overnight from individual colonies at $28{ }^{\circ} \mathrm{C}$ in YEB medium plus selective antibiotics, transferred to induction medium $(0.5 \%$ beef extract, $0.1 \%$ yeast extract, $0.5 \%$ peptone, $0.5 \%$ sucrose, $2 \mathrm{~mm} \mathrm{MgSO}$, $20 \mu \mathrm{m}$ acetosyringone, $10 \mathrm{~mm} \mathrm{MES}, \mathrm{pH}$ 5.6) plus antibiotics, and grown again overnight. The next day, cultures were resuspended with infiltration medium ( $10 \mathrm{~mm} \mathrm{MgCl}, 10 \mathrm{~mm} \mathrm{MES}, 200 \mu \mathrm{m}$ acetosyringone, $\mathrm{pH} 5.6$ with $\mathrm{OD}_{600}$ of 1.0), and incubated at room temperature
Table 1 Primers used for qRT-PCR and cloning

\begin{tabular}{lll}
\hline Primer name & \multicolumn{1}{c}{ Oligonucleotides } & \multicolumn{1}{c}{ Gene ID } \\
\hline SICaM1-a & CCA GAG TTC CTT AAC CTG ATG G & Solyc01g008950 \\
SICaM1-b & CTT TTC GCC TAG GTT TGT CAT C & \\
SICaM2-a & TCT GAG GAG GAG TTG AAA GAG G & Solyc10g081170 \\
SICaM2-b & TCA ACA TCA GCT TCC CTA ATC A & \\
SICaM3-a & GAT GGT AAT GGA ACC ATC GAC T & Solyc10g077010 \\
SICaM3-b & CAT CAG TGA GCT TCT CAC CAA G & Solyc11g072240 \\
SICaM4-a & TCA GAT CTC GGA GTT CAA AGA AG & \\
SICaM4-b & CAG GTT AAG GAA CTC AGG GAA GT & Solyc12g099990 \\
SICaM5-a & TTA ACT TGA TGG CTC GGA AGA T & \\
SICaM5-b & ACG AAT CAT CTC GTC AAC CTC T & Solyc03g098050 \\
SICaM6-a & ATC ACT TGG TCA GAA TCC CAC T & \\
SICaM6-b & AGC TGC AGA AAT AAA GCC ATT C & Solyc03g111720 \\
SIE4-a & ACC AGC AAT ATC TAG AGA AGG GTG & \\
SIE4-b & ATC ATT GTC ATG TTT ATT CAA ATT TAA AG & X55749 \\
SIActin-a & GAA ATA GCA TAA GAT GGC AGA CG & \\
SIActin-b & ATA CCC ACC ATC ACA CCA GTA T & \\
SICaM2-S1* & ggt ggt acCATG GCG GAT CAG CTG ACG G & \\
SICaM2-S2* & gga gga tCC CTT GGC CAT CAT GAC CTT AAC & \\
SICaM2-A1* & ggt ggt acCCTT GGC CAT CAT GAC CTT AAC & \\
SICaM2-A2* & gga gga tcCATG GCG GAT CAG CTG ACG G & \\
\hline
\end{tabular}

* Primers used for cloning S/CaM2 into the plant transformation vectors. The underlined are the restriction sites.

with gentle agitation (20 r.p.m.) for a minimum of 2 h. Cultures were injected into the early mature green fruits which were still attached to plants using a syringe with a $0.5-\mathrm{mm} \times 16-\mathrm{mm}$ needle. The needle was inserted into the fruit tissue through the blossom end. Because of differences in fruit size, the injection was terminated when the solution started running out the injection site. The agroinfiltrated fruits continued the developmental process in planta.

\section{Confocal laser scanning microscopy}

Thin slices of tomato fruits were placed in cover glass bottom petri dishes (MatTeck Corp., Ashland, MA, USA) for observation. A Zeiss ${ }^{\mathrm{TM}}$ LSM710 confocal laser scanning microscopy (Carl Zeiss Microscopy, Thornwood, NY, USA) system was utilized. The images were observed using a Zeiss Axio Observer $^{\mathrm{TM}}$ inverted microscope with a $10 \times 0.45 \mathrm{NA}$ Plan Apochromatic objective. Both differential interference contrast and fluorescence images were acquired simultaneously. A photomultiplier tube captured the light emitted from a $488 \mathrm{~nm}$ argon laser with a pin hole of $3.7 \mu \mathrm{m}$ passing through a MBS 488 filter with limits set between 492 and $543 \mathrm{~nm}$. Zeiss $Z_{\text {Zen }}{ }^{T M} 2012$ software was used to obtain 15-20 z-stack images to produce the $3 \mathrm{D}$ renderings, which were used to develop the $2 \mathrm{D}$ maximum intensity projections for publication.

\section{Colorimetric analysis}

A Minolta Chroma Meter CR-300 (Minolta Corp., Osaka, Japan) was used to assess the color of fruit surface. Three measurements per fruit and six fruits per treatment were taken. The means of value $a^{*}$ and $b^{*}$ were used to calculate the hue angle (Hue $\left.=\arctan \left(b^{*} / a^{*}\right)\right)$ and metric chrome value (Chroma $\left.=\left(a^{* 2}+b^{* 2}\right)^{1 / 2}\right)$. Student's $t$-test $(p<0.01)$ was used to determine the significant difference of different colorimetric parameters. The Chroma meter was calibrated with a standard white plate $(Y=94.00, x=0.3158$, $y=0.3322$ ).

\section{RESULTS}

Expression pattern during fruit development and ripening During tomato fruit development, all six calmodulin genes in the pericarp showed a double peak expression pattern (Figure 1). The first peak was flat and appeared between 10 and 30 DPA when the fruit size was expanding. Then the expression levels for calmodulins dropped to the lowest at mature green and/or breaker. After that, a sharp peak was observed at turning stage and started to decline after orange stage. As the fruit became red, their expression levels 


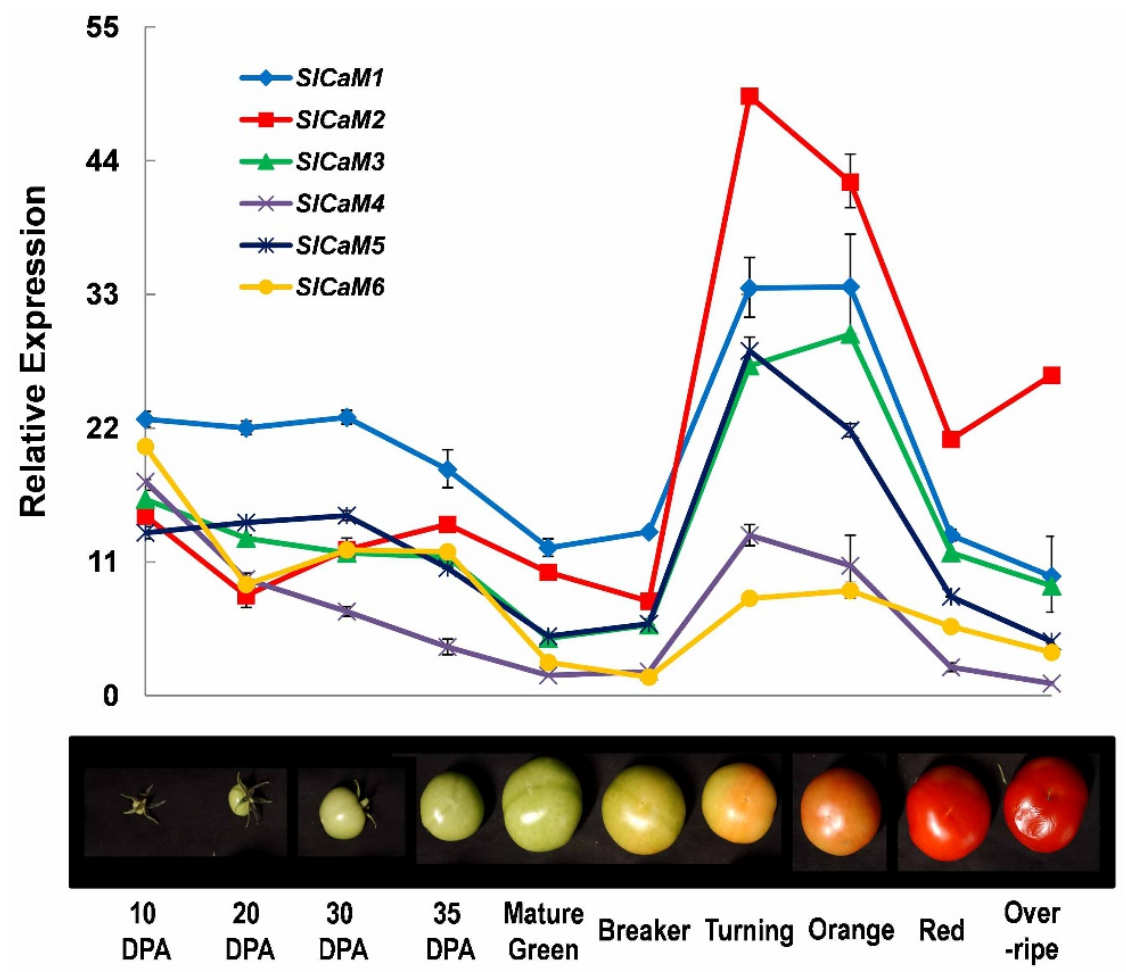

Figure 1. Expression patterns of SICaM genes during fruit development. Relative gene expression levels are shown following normalization with actin transcript values. Error bars represent standard error of the mean. For each gene, different letters indicate significant differences among mean values $(p<0.05)$. The bottom shows the fruit images at $10,20,30$, and 35 days post anthesis (DPA), mature green, breaker, turning, pink, red and overripe stages. The results are based on at least three repeats in three independent experiments.

declined rapidly. At over-ripe stage, the expression levels of all SICaMs except SICaM2 dropped to the bottom basal level. The most abundant calmodulin in unripe fruit (from 10 DPA to breaker stage) was SICaM1 which had over 22-fold more than the lowest expression by SICaM6 at breaker stage. However, after breaker stage, the expression of SICaM2 was significantly enhanced, and reached as high as $\sim 46$-fold at turning stage. Thus SICaM2 became the most abundant calmodulin during fruit ripening, followed by SICaM1, SICaM3 and SICaM5. SICaM4 and SICaM6 had the lowest expressions at most stages. Their second peak at turning stage was even lower than their first peak. However, the other four calmodulins had the highest expression at turning stages when their expression levels were doubled or tripled as compared to their first peak occurring during fruit enlargement. These results suggest that higher expression of SICaMs is required for both fruit enlargement and ripening. However, during the transition period, i.e., mature green and breaker stages, the suppression of SICaMs was needed.

Expression in non-fruit tissues

To investigate whether any SICaMs show the specific expression in fruit, we examined the expression level of SICAMs in non-fruit tissues, including leaves, roots and flowers. Since the highest expression level of most SICaMs in fruit occurred at turning stage, this stage fruit was added for comparative studies. As shown in Figure 2, SICaMs were detected in all non-fruit tissues. As compared to the turning stage fruits, all SICaMs had the comparable expression in roots, but much lower expression in flowers and leaves. In particular, leaves had the lowest expression for all SICaMs, which were usually less than $10 \%$ of the corresponding mRNA levels in either roots or fruits. Relatively, SICaM1 was the most abundant in roots where SICaM2 had the lowest expression. These results suggest that SICaM2 could be a fruit preference calmodulin gene.
Expression of SICaMs are changed in tomato ripening mutants To determine whether the reduced expression of SICaMs at mature green and breaker stages has any relationship to fruit ripening, we compared the expression levels of SICaMs in the fruits from wildtype and three ripening-mutants, rin, Nor and $\mathrm{Nr}$ (Figure 3). First, we

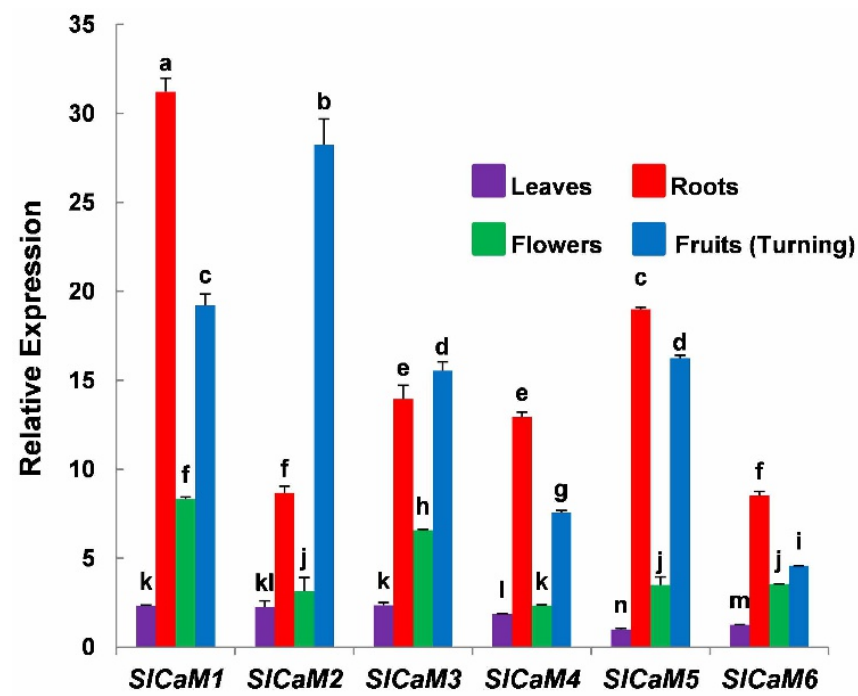

Figure 2. Expression patterns of SICaM genes in non-fruit tissues. Relative gene expression levels are shown following normalization with actin transcript values. Error bars represent standard error of the mean. For each gene, different letters indicate significant differences among mean values $(p<0.05)$. The results are based on at least three repeats in three independent experiments. 
SICaM1

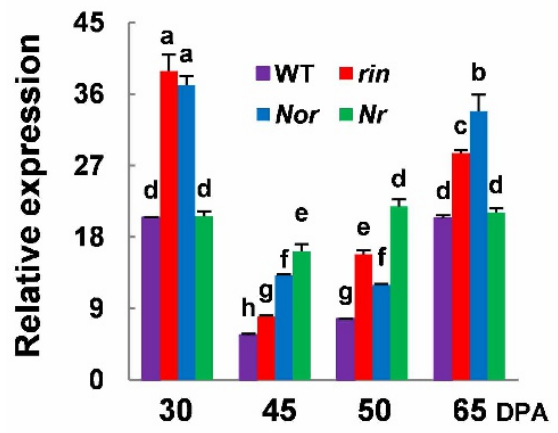

SICaM4

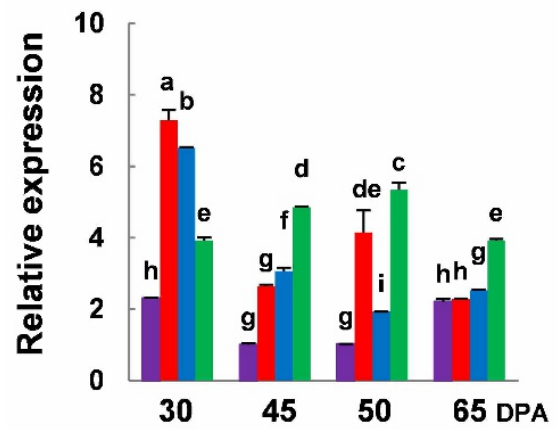

SICaM2

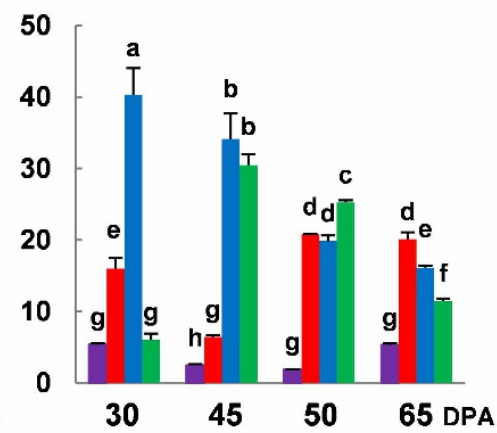

SICaM3
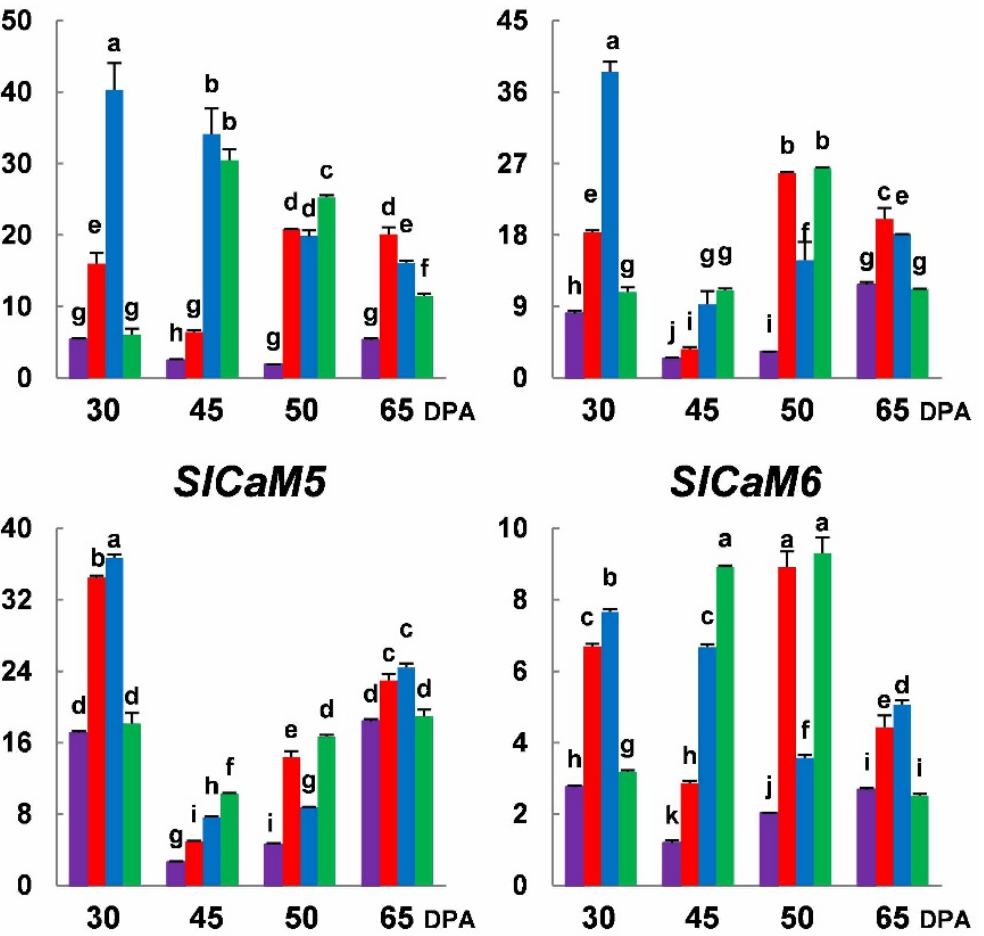

Figure 3. Expression patterns of S/CaMs in tomato ripening mutant fruits. Relative gene expression levels are shown following normalization with actin transcript values. Error bars represent standard error of the mean. For each gene, different letters indicate significant differences among mean values $(p<0.05)$. The results are based on at least three repeats in three independent experiments.

analyzed the expression of S/CaMs at 45 and 50 DPA in these mutants which corresponded to the mature green and breaker stages in wild-type fruit. Interestingly, all three mutants, particularly Nor and $\mathrm{Nr}$ showed significantly higher expression for all SICaMs at both stages. At 45 DPA, the most abundant calmodulin gene in Nor and $\mathrm{Nr}$ was SICaM2. Its expression level in Nor and $\mathrm{Nr}$ was about 35and 30 -fold higher than wild-type, respectively. At 50 DPA, the expression levels of SICAM2, SICaM3 and SICaM1 were the top three. We further examined the expressions in those mutant fruits at earlier stage (30 DPA) and later stage (65 DPA, equivalent to red stage in wild-type). In most cases, SICaMs in three mutants had higher expression than those in wild-type. Occasionally, some genes, e.g., SICaM1, SICaM3, SICaM5 and SICaM6, in some mutants, e.g., $\mathrm{Nr}$, showed the comparable expression level to wild-type. Thus generally speaking, the expression level for SICaMs were high in all ripening mutants at all stages. However, the expression patters for most SICAMs in mutants were low at mature green and/or breaker stages; a double peak phenomenon was observed in wild-type. Nevertheless, the expression of SICaM2, SICaM4 and SICaM6 was exceptional in Nor and Nr. For instance, SICaM2 displayed a gradual decrease from 30 DPA to 65 DPA in Nor. SICaM4 had no much change for all the four stages in $\mathrm{Nr}$, whereas SICaM6 displayed higher expression in $\mathrm{Nr}$ at 45 and 50 DPA than at 30 and 65 DPA.

SICAMs are ethylene responsive genes

Tomato fruit ripening is correlated to ethylene level. Nearly no endogenous ethylene was produced at mature green stage. Ethylene increased at breaker stage, and reached maximum at orange stages. ${ }^{7}$ Thus, we selected mature green stage fruits for ethylene treatment in order to define whether all SICAM genes in fruits are responsive to ethylene. All SICaMs showed positive responses to ethylene treatment as early as $1 \mathrm{~h}$ after treatment, and peaked at $4 \mathrm{~h}$ after treatment (Figure 4). In particular, SICaM2 exhibited the highest response to ethylene. Ethylene triggered SICaM2 over $\sim 15$-fold and $\sim 45$-fold at 1 and $4 \mathrm{~h}$ after treatment. In comparison, the expression levels of other SICaMs were boosted threeto fivefold by ethylene at four hours after treatment. E4 was a defined ethylene responsive gene, ${ }^{33}$ and showed dramatic response to ethylene treatment, which indicated that ethylene treatment was successful. These results demonstrate that all SICaMs, in particular SICaM2, are ethylene responsive genes.

\section{Alteration of SICaM2 level affects fruit ripening}

Based upon the expression patterns of SICaMs during fruit development in wild-type and ripe mutants and their response to ethylene treatment, it seemed that SICaM2 could be a stronger candidate to function during fruit ripening. Thus, we selected it for further functional analysis in planta. To quickly assess the transgene expression in fruit, the agroinjection method was utilized to transiently express the candidate genes in the early mature-green fruit. We first injected Agrobacterium cultures carrying a control vector (pDL198) containing 35S: GFP into fruit. Green fluorescence was detected after $36 \mathrm{~h}$, and reached a maximum at $48 \mathrm{~h}$ (Figure $5 \mathrm{a}$ ). After that, the green fluorescence gradually faded, and completely disappeared at day 6. However, no green fluorescence was detected in the fruit injected with Agrobacterium only. These results indicate that the transgene can be temporally highly expressed at the late mature green stage when agroinfiltration is performed in early mature green fruit.

Similarly, SICAM2- sense and antisense constructs were agroinjected into early mature green fruits. Ninety-six hours after injection (day 4), the expression level of SICaM2 in control (pDL198 vector alone) was about twofold higher than non-agroinfiltrated fruit (wild-type) (Figure 5b), suggesting that Agrobacterium itself slightly stimulated the endogenous SICaM2 expression. However, 
SICaM1

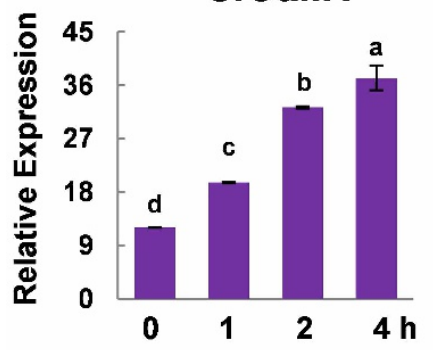

SICaM5

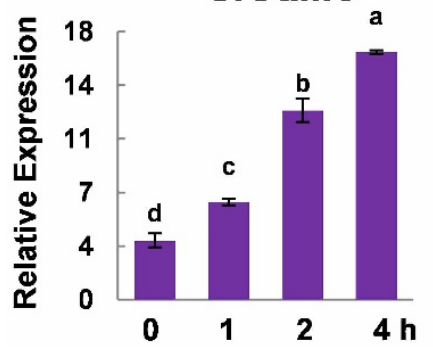

SICaM2

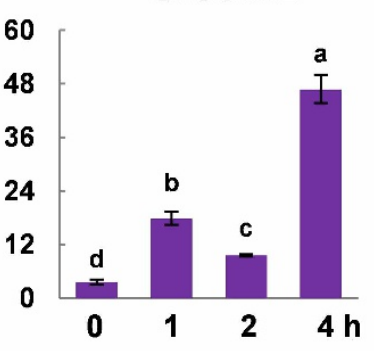

SICaM3

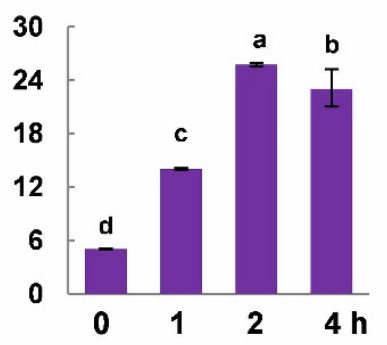

SICaM4

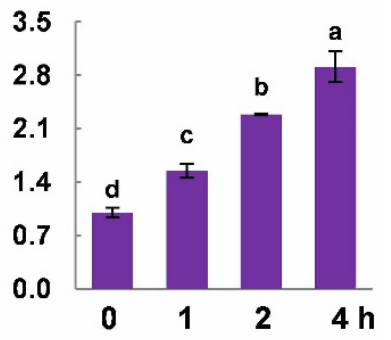

\section{SICaM6}
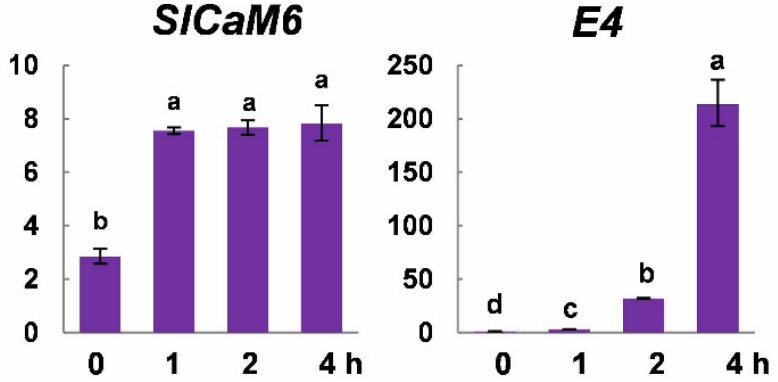

Figure 4. SICaMs expression levels are stimulated by ethylene treatment. Tomato fruits (cv. Rutgers) at mature green stage were treated with $100 \mathrm{ppm}$ ethylene for different time periods as indicated. Relative gene expression levels are shown following normalization with actin transcript values. Error bars represent standard error of the mean. For each gene, different letters indicate significant differences among mean values $(p<0.05)$. The results are based on at least three repeats in three independent experiments.

as compared to the vector alone control, SICaM2 in the sense fruit was increased by over fivefold at day 4 . In contrast, the expression of SICAM2 in the antisense fruit was reduced by 4-5 times. In addition, no significant change in the level of other calmodulins was detected in the sense and control fruit. Instead, the expression levels of other calmodulins in the antisense fruit were also reduced by 1.6- to 3.6-fold, suggesting that the antisense SICaM2 can reduce total level of calmodulins, too (data not shown), due to the high homology between all calmodulins. On day 6 , the antisense fruits began the color change from green to white, while no obvious color change was observed in control and sense fruits until days 8 and 9. On day 11 , the antisense fruit turned to orange/red (Figure $5 c$, when wild-type fruit (without agroinfiltration) reached turning/orange stage (data not shown). In comparison, the vector alone control fruit reached breaker/turning, and sense fruit was at late breaker (Figure $5 \mathrm{c}$ ). The difference of fruit surface color on day 11 was further analyzed by a colorimeter (Table 2 ). There were no much differences in $b^{*}$ value in all types of fruits. The antisense fruits had a slightly lower $L^{*}$ and higher Chroma value than other fruits. However, the significant difference $(p<0.01)$ in $a^{*}$ value was detected between the antisense fruits and sense fruits. The antisense fruits had $a^{*}$ value of 20.6, whereas $a^{*}$ value for the sense fruits was -5.3 . Accordingly, the Hue value for the antisense fruit was 55.9, much lower than the sense fruits (99.3). As for the control (35S: GFP) fruits and wild-type fruits (no agroinfiltration), their $a^{*}$ value and hue were 1 and 87.9, 5.5 and 79, respectively. Thus the fruit surface color of the antisense fruits was much redder than others, while the sense fruits were more greenish than all other fruits including the control fruits.

Further gene expression examination at day 11 showed that the expression levels of SICaM2 in all fruits were increased as compared to those at day 4. However, SICAM2 in the antisense fruit was increased by 40 - to 50 -fold, whereas its levels in control and sense fruit were increased by $\sim 21$ - and $\sim 9$-fold, respectively (Figure $5 \mathrm{~b}$ ). The expression of ethylene-responsive gene $E 4$ in the antisense fruit showed 38 and 105 times higher than the control fruit and sense fruit at day 11 , respectively (data not shown), suggesting that there was more endogenous ethylene produced in the antisense fruit. These results indicate that temporally reducing SICAM2 (maybe total calmodulins) at mature green can facilitate fruit ripening.

\section{DISCUSSION}

Tomato fruit development includes two periods, fruit enlargement and fruit ripening. ${ }^{1,3}$ Fruit enlargement results from both cell division and cell elongation. After fruit reaches the maximum size at mature green, the ripening process starts at breaker as shown by the degradation of chlorophyll and formation of carotenoids. In this study, we analyzed the gene expression profiles of the calmodulin gene family during fruit development, and found that the expression of all the calmodulins exhibited a double peak pattern, one peak at fruit enlargement stages, and another during fruit color changes from mature green to red (Figure 1). It is well documented that calcium/calmodulin is critical for cell division because the distribution of calmodulins is highly located in proliferating cells such as root tip, young shoot and developing embryos/seed, but low in expanding leaves and the base of stems. ${ }^{34-37}$ Calmodulin also appears high in cells with specialized events and signaling, such as pollen tube growth, cotton fiber elongation and coleoptiles elongation. $^{38-40}$ In tomato, SUN, a calmodulin-binding IQD family protein is shown to control fruit elongation. ${ }^{28}$ Hence high calmodulin expression during fruit enlargement might contribute to promote cell division and cell elongation. Once the fruit reached the maximal size at mature green, the level of calmodulin rapidly decreased (Figure 1). All these results suggest that calmodulins play a role for fruit size increase.

It was expected that the calmodulin expression is kept at a low level at breaker when fruit changes color due to the chlorophyll breakdown. Calcium treatment has been shown to delay the leaf senescence. ${ }^{41,42}$ Knockouts of calcium/calmodulin-binding proteins such as SR1/CaMTA3, CNGC and MLO showed early leaf senescence and chlorosis. ${ }^{43,44}$ Thus the low expression of calmodulin in breaker fruit could result to the chlorophyll degradation. However, after breaker, expression of calmodulins was 


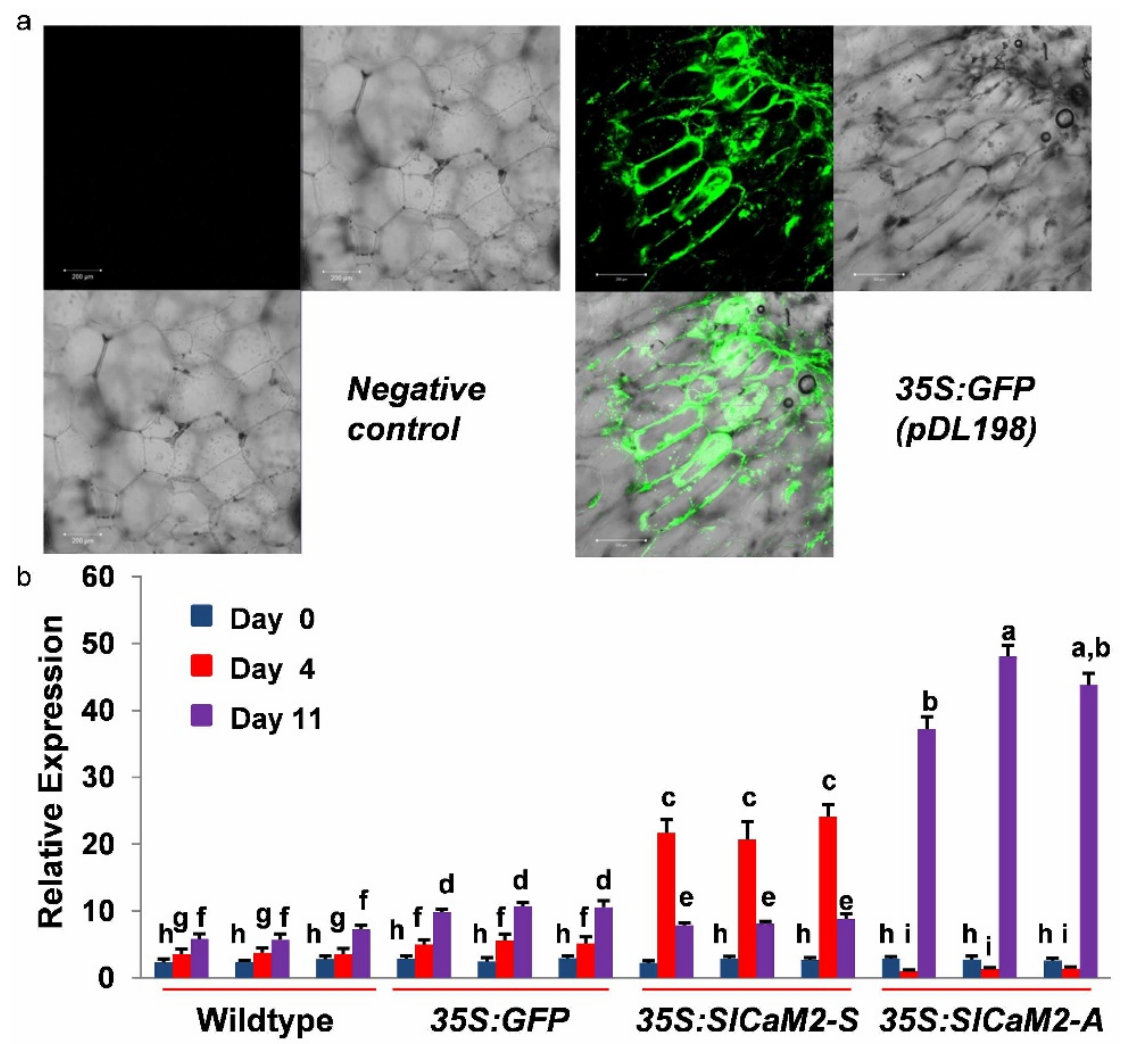

C

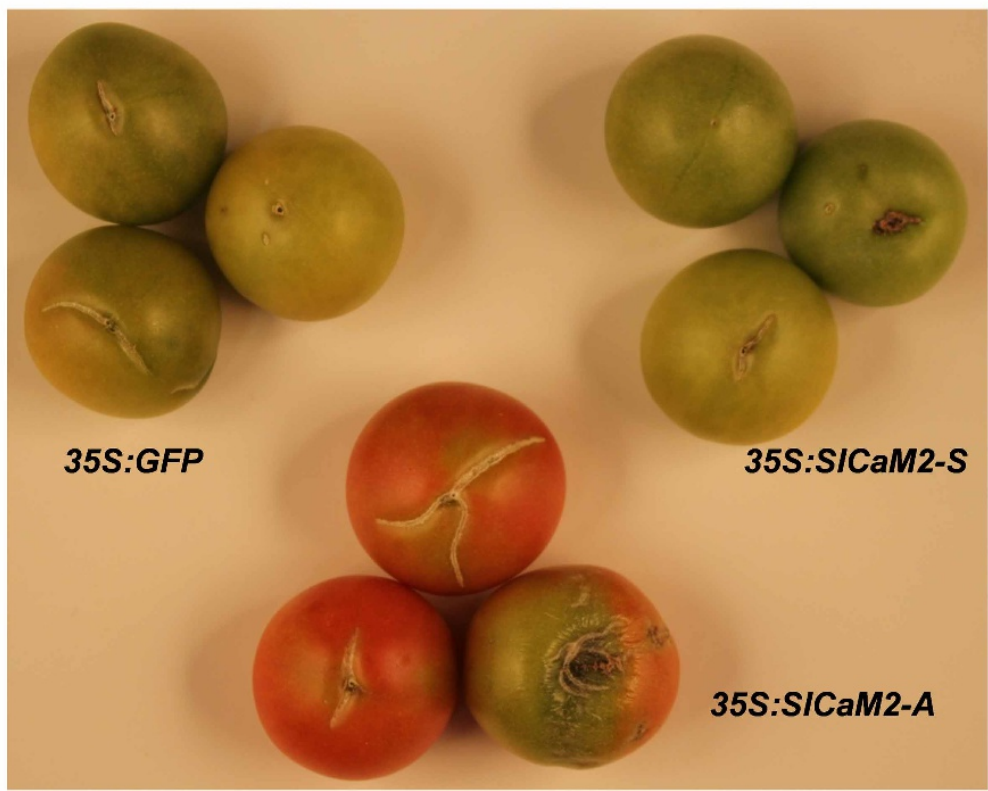

Figure 5. Expression level of SICaM2 in fruit affects fruit ripening. The early mature green fruit were agroinfiltrated with Agrobacterium carrying different constructs. 35S: GFP, pDL198 empty vector (control); 35S: SICaM2-Sense, pDL198 carrying SICaM2 in the sense orientation downstream of 35S promoter; 35S: SICaM2-Antisense, pDL198 carrying SICaM2 in the antisense orientation downstream of 35S promoter. (a) Confocal image of green fluorescence protein in agroinjected fruit tissue. The images were taken $48 \mathrm{~h}$ after agroinjection (day 4). Bar $=200 \mu \mathrm{m}$. Negative control, agroinfiltrated with Agrobacterium only. (b) Examination of expression levels of SICaM2 in different agroinfiltrated fruits. Days 0, 4 and 11 after agroinfiltration, a piece of pericarp tissue from each fruit was used for RT-qPCR analysis. Relative gene expression levels are shown following normalization with actin transcript values. Different letters indicate significant differences among mean values $(p<0.05)$. (c) Fruits at Day 11 after agroinfiltration show the difference in fruit color and maturity after agroinfiltrated with different constructs.

dramatically stimulated and reached the second peak at pink stage when they were even higher than the first peak during fruit enlargement (Figure 1). This could be mainly stimulated by ethylene burst occurring after late breaker ${ }^{7,45}$ since all calmodulins were ethylene-responsive (Figure 4). These results suggest that calmodulins acts in the ethylene-dependent ripening process. 
Table 2 Color parameters and ripe indexes for agroinfiltrated fruits (Day 11)

\begin{tabular}{|c|c|c|c|c|c|}
\hline Fruits $^{1}$ & $L^{*}$ & $a^{*}$ & $b^{*}$ & Hue & Chroma \\
\hline Wild-type & $52.4 \pm 0.6^{a}$ & $5.5 \pm 0.8^{c}$ & $28.5 \pm 1.2^{\mathrm{a}}$ & $79.0 \pm 1.8^{c}$ & $29.0 \pm 1.1^{\mathrm{a}}$ \\
\hline 35S:GFP & $53.1 \pm 0.4^{a}$ & $1.0 \pm 0.3^{b}$ & $29.3 \pm 0.6^{a}$ & $87.9 \pm 0.7^{b}$ & $29.3 \pm 0.6^{a}$ \\
\hline 35S:SICaM2-S & $54.6 \pm 1.0^{\mathrm{a}}$ & $-4.6 \pm 0.7^{a}$ & $28.4 \pm 1.2^{\mathrm{a}}$ & $99.3 \pm 1.2^{\mathrm{a}}$ & $28.8 \pm 1.1^{\mathrm{a}}$ \\
\hline
\end{tabular}

${ }^{1}$ Wild-type: no agroinfiltration; 35S:GFP: pDL198 empty vector; 35S:SICaM2-S: pDL198 carrying SICaM2 in the sense orientation downstream of 35 S promoter; 35S:SICaM2-A, pDL198 carrying SICaM2 in the antisense orientation downstream of 35 S promoter.

Nevertheless, our data indicate that calmodulins may play an important role to regulate fruit ripening upstream of ethylene signaling, too. First, calmodulin levels in three ripening mutants were significantly higher than wild-type in all the examined stages. In particular, S/CaMs in those mutants did not show the obvious double peak pattern (Figure 3). Instead, all the three ripening mutants had the significantly high expression of S/CaMs at the stages corresponding to mature green and breaker in wild-type fruit. Second, temporally overexpressing SICaM2 in the mature green fruit delayed the maturation process, while repressing SICAM2 led to the accelerated ripening (Figure 5). Hence, the reduced expression of calmodulins at mature green and breaker could be a prerequisite for fruit to enter the ripening process. If the calmodulin level cannot be reduced at those stages, fruit cannot initiate the ripening process as shown in ripening mutants. Notably the similar expression pattern was observed in a calmodulin-regulated transcription factor SISR2, ${ }^{30}$ and $\beta$-galactosidase gene TBG5 at the same stages. ${ }^{46} \beta$-galactosidase is important for hemicellulosic modifications that occur during cell division, cell growth and fruit ripening. Further studies are necessary to define whether they are the direct and/or indirect downstream targets of SICaM2.

Calmodulin belongs to a small gene family in plants. Multiple calmodulin genes often show differential expression in tissues, developmental stages, and in response to numerous external and internal stimuli such as temperature changes, light and pathogen attacks, and to hormones such as abscisic acid and ethylene. ${ }^{16-19}$ It is believed that individual calmodulin genes could have unique functional application and significance. ${ }^{17,47}$ For instance, Arabidopsis contains seven calmodulin genes encode four highly conserved isoforms. A loss-of-function mutant in AtCaM2 affects pollen germination. ${ }^{48}$ However, the atcam3 knockout mutant exhibits reduced thermotolerance after heat treatment, whereas overexpressing AtCaM3 significantly increases thermotolerance. ${ }^{49}$ Tomato has six calmodulins encoding four isoforms. ${ }^{21}$ In our study, SICaM2 showed the most dramatic changes during the transition period from mature green to ripe (Figure 1) and the most responsive to ethylene treatment (Figure 4). The manipulation of its expression level during this period clearly affected the fruit maturation process (Figure 5). Thereby, among all the calmodulins, S/CaM2 could be a major player to regulate fruit ripening, especially the ethylene-coordinated fruit ripening, although we cannot exclude the possible role of other calmodulins.

In conclusion, we have investigated six calmodulin expression profiles in tomato wild-type and ripening mutants during fruit development, and carried out the functional studies of SICaM2 during the transition period from mature green to ripe. Based upon our data, we propose a model to describe SICaMs' role during fruit development and ripening (Figure 6). The expression pattern of SICaMs is regulated by development signals. During fruit enlargement, highly expressed SICaMs could contribute to cell division and elongation. After mature green, SICaMs could play double roles to regulate fruit ripening. Prior to the ethylene burst, the downregulation of SICaMs is required for fruit to initiate the ripening process. This process is ethyleneindependent and may be present in both climacteric and nonclimacteric fruits. The details of the regulatory cascade in this process still like a "black box". After the ethylene burst, SICaMs

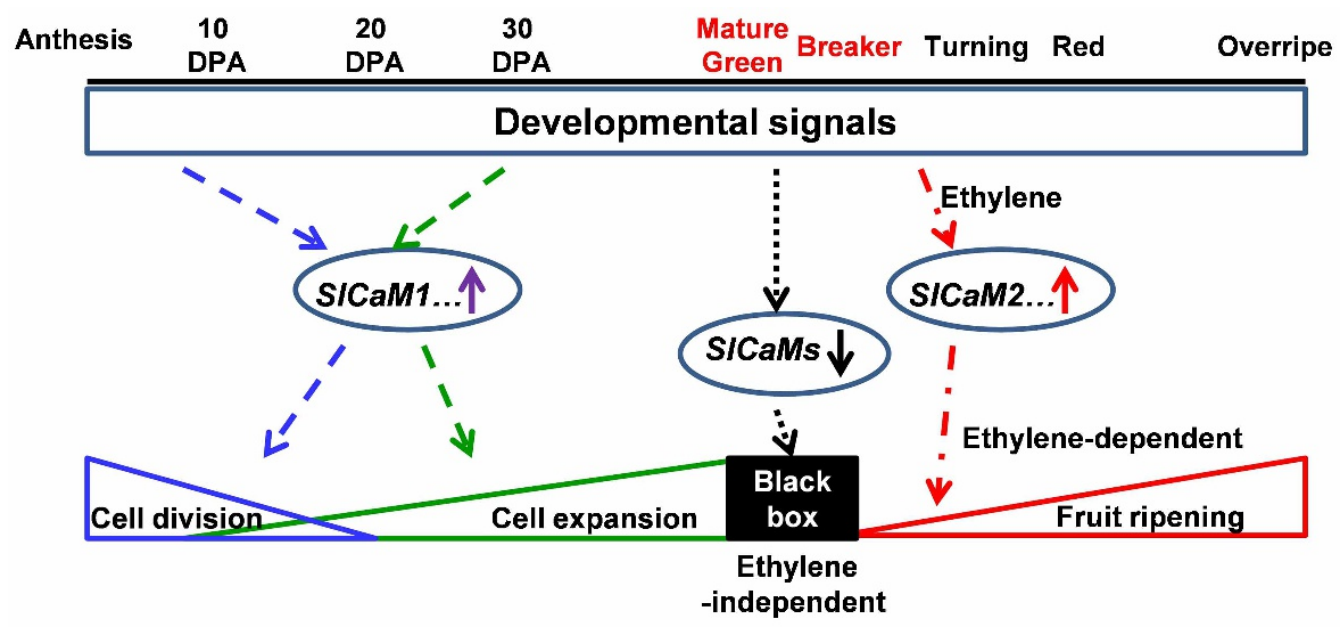

Figure 6. Schematic illustration of the proposed model for calmodulins' function during tomato fruit development and ripening. High expression of calmodulin during fruit enlargement could contribute to cell division and expansion. After ethylene burst, high calmodulin expression could be involved in ethylene-dependent ripening. Dowregulation of calmodulin during the transition period is critical for fruit to initiate the ripening (an ethylene independent event) although the mechanics is still not clear (like a 'black box'). The time line and stages may vary among different cultivars and different conditions. 
are rapidly stimulated by ethylene to participate in the ethylene coordinated rapid ripening. Further characterization of the SICaMs-regulated signal transduction pathway in relation to ethylene-dependent and -independent ripenings and the ripening genes using the omics approaches ${ }^{50}$ will shed light on the understanding of fruit ripening mechanics. Furthermore, it will be a great interest to determine whether the similar ethyleneindependent regulation by calmodulin exists in other species, especially non-climacteric fruits.

\section{COMPETING INTERESTS}

The authors have no conflict of interest.

\section{ACKNOWLEDGEMENTS}

We thank Ernest Paroczay and Ziying Zou for their technical support and Liqun Du for providing pDL198 plasmid. Use of a company or product name by the US Department of Agriculture does not imply approval or recommendation of the product to the exclusion of others that may also be suitable. This research was funded by USDA-ARS NP306 project no. 124543000-012-00D.

\section{REFERENCES}

1 Giovannoni JJ. Fruit ripening mutants yield insights into ripening control. Curr Opin Plant Biol 2007; 10: 283-289.

2 Gillaspy G, Bendavid H, Gruissem W. Fruits-a developmental perspective. Plant Cell 1993; 5: 1439-1451.

3 Matas AJ, Gapper NE, Chung MY, Giovannoni JJ, Rose JK. Biology and genetic engineering of fruit maturation for enhanced quality and shelf-life. Curr Opin Biotechnol 2009; 20: 197-203.

4 Seymour GB, Ostergaard L, Chapman NH, Knapp S, Martin C. Fruit development and ripening. Annu Rev Plant Biol 2013; 64: 219-241.

5 Vrebalov J, Ruezinsky D, Padmanabhan V et al. A MADS-box gene necessary for fruit ripening at the tomato ripening-inhibitor (Rin) locus. Science 2002; 296 343-346.

6 Wilkinson JQ, Lanahan MB, Yen HC, Giovannoni JJ, Klee HJ. An ethylene-inducible component of signal-transduction encoded by Never-ripe. Science 1995; 270 1807-1809.

7 Giovannoni JJ. Genetic regulation of fruit development and ripening. Plant Cell 2004; 16: S170-S180.

8 Poovaiah BW. Role of calcium in prolonging storage life of fruits and vegetables. Food Technol-Chicago 1986; 40: 86-89.

9 Cheour F, Willemot C, Arul J et al. Foliar application of calcium-chloride delays postharvest ripening of strawberry. J Am Soc Hort Sci 1990; 115: 789-792.

10 Martin-Diana AB, Rico D, Frias JM, Barat JM, Henehan GT, Barry-Ryan C. Calcium for extending the shelf life of fresh whole and minimally processed fruits and vegetables: a review. Trends Food Sci Technol 2007; 18: 210-218.

11 Sams CE, Conway WS, Abbott JA, Lewis RJ, Benshalom N. Firmness and decay of apples following postharvest pressure infiltration of calcium and heat-treatment. J Am Soc Hort Sci 1993; 118: 623-627.

12 Liu H, Chen FS, Yang HS et al. Effect of calcium treatment on nanostructure of chelate-soluble pectin and physicochemical and textural properties of apricot fruits. Food Res Int 2009; 42: 1131-1140.

13 Paliyath G, Poovaiah BW, Munske GR, Magnuson JA. Membrane fluidity in senescing apples-effects of temperature and calcium. Plant Cell Physiol 1984; 25: 1083-1087.

14 DeFalco TA, Bender KW, Snedden WA. Breaking the code: $\mathrm{Ca}^{2+}$ sensors in plant signalling. Biochem J 2010; 425: 27-40.

15 Kudla J, Batistic O, Hashimoto K. Calcium signals: the lead currency of plant information processing. Plant Cell 2010; 22: 541-563.

16 Reddy ASN, Ali GS, Celesnik H, Day IS. Coping with stresses: roles of calciumand calcium/calmodulin-regulated gene expression. Plant Cell 2011; 23: 2010 2032.

17 Yang T, Poovaiah BW. Calcium/calmodulin-mediated signal network in plants. Trends Plant Sci 2003; 8: 505-512.

18 Bouche N, Yellin A, Snedden WA, Fromm H. Plant-specific calmodulin-binding proteins. Annu Rev Plant Biol 2005; 56: 435-466.

19 Poovaiah BW, Du LQ, Wang HZ, Yang TB. Recent advances in calcium/calmodulinmediated signaling with an emphasis on plant-microbe interactions. Plant Physiol 2013; 163: 531-542

20 Perochon A, Aldon D, Galaud JP, Ranty B. Calmodulin and calmodulin-like proteins in plant calcium signaling. Biochimie 2011; 93: 2048-2053.
21 Zhao Y, Liu W, Xu YP, Cao JY, Braam J, Cai XZ. Genome-wide identification and functional analyses of calmodulin genes in Solanaceous species. BMC Plant Biol 2013; 13: 70.

22 Bergey DR, Ryan CA. Wound- and systemin-inducible calmodulin gene expression in tomato leaves. Plant Mol Biol 1999; 40: 815-823.

23 Akihiro T, Koike S, Tani $R$ et al. Biochemical mechanism on GABA accumulation during fruit development in tomato. Plant Cell Physiol 2008; 49: 1378-1389.

24 Baum G, Chen Y, Arazi T, Takatsuji H, Fromm H. A plant glutamate decarboxylase containing a calmodulin binding domain. Cloning, sequence, and functional analysis. J Biol Chem 1993; 268: 19610-19617.

25 Inoue K, Shirai T, Ochiai H et al. Blood-pressure-lowering effect of a novel fermented milk containing gamma-aminobutyric acid (GABA) in mild hypertensives. Eur J Clin Nutr 2003; 57: 490-495.

26 van der Knaap E, Sanyal A, Jackson SA, Tanksley SD. High-resolution fine mapping and fluorescence in situ hybridization analysis of sun, a locus controlling tomato fruit shape, reveals a region of the tomato genome prone to DNA rearrangements. Genetics 2004; 168: 2127-2140.

27 Xiao H, Jiang N, Schaffner E, Stockinger EJ, van der Knaap E. A retrotransposonmediated gene duplication underlies morphological variation of tomato fruit. Science 2008; 319: 1527-1530.

28 Rodriguez GR, Munos S, Anderson C et al. Distribution of SUN, OVATE, LC, and FAS in the tomato germplasm and the relationship to fruit shape diversity. Plant Physiol 2011; 156: 275-285.

29 Yang TB, Peng H, Whitaker BD, Jurick WM. Differential expression of calcium/ calmodulin-regulated SISRs in response to abiotic and biotic stresses in tomato fruit. Physiol Plantarum 2013; 148: 445-455.

30 Yang TB, Peng H, Whitaker BD, Conway WS. Characterization of a calcium/ calmodulin-regulated SR/CAMTA gene family during tomato fruit development and ripening. BMC Plant Biol 2012; 12: 19.

31 Du LQ, Ali GS, Simons KA et al. $\mathrm{Ca}^{2+}$ /calmodulin regulates salicylic-acid-mediated plant immunity. Nature 2009; 457: 1154-1116.

32 Orzaez D, Mirabel S, Wieland WH, Granell A. Agroinjection of tomato fruits. A tool for rapid functional analysis of transgenes directly in fruit. Plant Physiol 2006; 140: 3-11.

33 Lincoln JE, Cordes S, Read E, Fischer RL. Regulation of gene expression by ethylene during Lycopersicon esculentum (tomato) fruit development. Proc Natl Acad Sci USA 1987; 84: 2793-2797.

34 Allan E, Trewavas A. Quantitative changes in calmodulin and NAD kinase during early cell-development in the root apex of Pisum sativum L. Planta 1985; 165: 493501.

35 Yang T, Lev-Yadun S, Feldman M, Fromm H. Developmentally regulated organ-, tissue-, and cell-specific expression of calmodulin genes in common wheat. Plant Mol Biol 1998; 37: 109-120.

36 Ling V, Perera I, Zielinski RE. Primary structures of Arabidopsis calmodulin isoforms deduced from the sequences of cDNA clones. Plant Physiol 1991; 96 1196-1202.

37 Nelissen H, Clarke JH, de Block M et al. DRL1, a homolog of the yeast TOT4/KT112 protein, has a function in meristem activity and organ growth in plants. Plant Cell 2003; 15: 639-654.

38 Tang WX, Tu LL, Yang XY et al. The calcium sensor GhCaM7 promotes cotton fiber elongation by modulating reactive oxygen species (ROS) production. New Phytol 2014; 202: 509-520.

39 Park JE, Kim YS, Yoon HK, Park CM. Functional characterization of a small auxinup RNA gene in apical hook development in Arabidopsis. Plant Sci 2007; 172: 150-157.

40 Lazzaro MD, Marom EY, Reddy ASN. Polarized cell growth, organelle motility, and cytoskeletal organization in conifer pollen tube tips are regulated by KCBP, the calmodulin-binding kinesin. Planta 2013; 238: 587-597.

41 Cheour F, Arul J, Makhlouf J, Willemot C. Delay of membrane lipid degradation by calcium treatment during cabbage leaf senescence. Plant Physiol 1992; 100: 16561660.

42 Poovaiah BW, Leopold AC. Deferral of leaf senescence with calcium. Plant Physiol 1973; 52: 236-239.

43 Nie HZ, Zhao CZ, Wu GH, Wu YY, Chen YF, Tang DZ. SR1, a calmodulin-binding transcription factor, modulates plant defense and ethylene-induced senescence by directly regulating NDR1 and EIN3. Plant Physiol 2012; 158: 18471859.

44 Consonni $\mathrm{C}$, Humphry $\mathrm{ME}$, Hartmann HA et al. Conserved requirement for a plant host cell protein in powdery mildew pathogenesis. Nat Genet 2006; 38 : 716-720.

45 Alexander L, Grierson D. Ethylene biosynthesis and action in tomato: a model for climacteric fruit ripening. J Exp Bot 2002; 53: 2039-2055. 
46 Smith DL, Gross KC. A family of at least seven beta-galactosidase genes is expressed during tomato fruit development. Plant Physiol 2000; 123: 11731183.

47 Snedden WA, Fromm H. Calmodulin as a versatile calcium signal transducer in plants. New Phytologist 2001; 151: 35-66.

48 Landoni M, de Francesco A, Galbiati M, Tonelli C. A loss-of-function mutation in Calmodulin2 gene affects pollen germination in Arabidopsis thaliana. Plant Mol Biology 2010; 74: 235-247.

49 Zhang W, Zhou RG, Gao YJ et al. Molecular and genetic evidence for the key role of AtCaM3 in heat-shock signal transduction in Arabidopsis. Plant Physiol 2009; 149: 1773-1784.
50 Gapper NE, Giovannoni JJ, Watkins CB. Understanding development and ripening of fruit crops in an 'omics' era. Hort Res 2014; 1: 14034.

(c) (1) () $\odot$ This work is licensed under a Creative Commons AttributionNonCommercial-NoDerivs 3.0 Unported License. The images or other third party material in this article are included in the article's Creative Commons license, unless indicated otherwise in the credit line; if the material is not included under the Creative Commons license, users will need to obtain permission from the license holder to reproduce the material. To view a copy of this license, visit http:// creativecommons.org/licenses/by-nc-nd/3.0/ 